\title{
Disadvantaged black and coloured infants in two urban communities in the Western Cape, South Africa differ in micronutrient status
}

\author{
A Oelofse ${ }^{1, *}$, JMA Van Raaii ${ }^{2}$, AJS Benadé ${ }^{2}$, MA Dhansay ${ }^{1}$, JJM Tolboom $^{3}$ and \\ JGAJ Hautvast ${ }^{2}$ \\ ${ }^{1}$ Nutrition Intervention Research Unit, Medical Research Council, PO Box 19070, Tygerberg 7505, South Africa: \\ ${ }^{2}$ Division of Human Nutrition and Epidemiology, Wageningen University, Wageningen, The Netherlands: \\ ${ }^{3}$ Department of Paediatrics, Catholic University of Nijmegen, The Netherlands
}

Submitted 12 December 2000: Accepted 24 August 2001

\begin{abstract}
Objectives: To determine the nutritional and health status of urban infants in two disadvantaged communities in the Western Cape, South Africa with special reference to micronutrient status. The results of this study will serve to plan an intervention study in these communities in the same age group.

Design: Cross-sectional study.

Setting: Two disadvantaged urban black and 'coloured' communities in the Western Cape, South Africa.

Subjects: Sixty infants aged 6-12 months from each community.

Outcome measures: Dietary intake, anthropometric measurements, micronutrient status and psychomotor development.

Results: Stunting and underweight were more prevalent in coloured infants (18\% and $7 \%$, respectively) than in black infants ( $8 \%$ and $2 \%$, respectively). Anaemia (haemoglobin $(\mathrm{Hb})<11 \mathrm{~g} \mathrm{dl}^{-1}$ ) was prevalent in $64 \%$ of coloured and $83 \%$ of black infants. Iron-deficiency anaemia $\left(\mathrm{Hb}<11 \mathrm{~g} \mathrm{dl}^{-1}\right.$ and ferritin $<10 \mathrm{ng} \mathrm{ml}^{-1}$ ) was found in $32 \%$ of coloured infants and in $46 \%$ of black infants. Zinc deficiency was prevalent in $35 \%$ and $33 \%$ of the coloured and black infants, respectively. Marginal vitamin A deficiency (serum retinol $<20 \mu \mathrm{g} \mathrm{dl}^{-1}$ ) was observed in $23 \%$ of black infants compared with $2 \%$ of coloured infants. Of black infants, $43 \%$ and of coloured infants $6 \%$ were deficient in two or more micronutrients. Six per cent of coloured infants had C-reactive protein concentrations above $5 \mathrm{mgl}^{-1}$ compared with $38 \%$ of the black infants. The dietary intake of micronutrients was in general lower in black infants than in coloured infants. The overall psychomotor development, assessed by the Denver Developmental Screening Test, was different between the two groups. The coloured infants scored higher in three out of the four categories as well as in their overall score.

Conclusions: This study shows that information on stunting and wasting only in urban disadvantaged infants is not sufficient to make recommendations about specific community intervention programmes. Information on the micronutrient status, independent of wasting and stunting, is necessary to design nutrition programmes for different communities. The study also showed a substantially higher prevalence of micronutrient deficiencies among black infants.
\end{abstract}

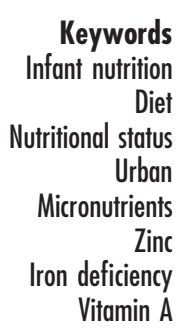

The disadvantaged circumstances in which families live in peri-urban communities in developing countries and its consequences on health are reported frequently. Infants growing up in these communities are vulnerable with reference to health and nutrition ${ }^{1,2}$.

There are no detailed reports in South Africa comparing the nutritional status of different ethnic groups of infants in disadvantaged communities. Often the age groups studied include a wider age range $\mathrm{e}^{3,4}$. Conclusions with regard to infants aged 6-12 months are limited in such studies. Specific information on infants is necessary in order to plan community nutrition intervention programmes to reduce the vulnerability of young children at the age of weaning ${ }^{5}$.

Adequate nutritional status is a prerequisite for good physical and mental development of vulnerable commu- 
nities $^{1,6}$. In these communities the emphasis is mostly on the nutritional quantity of the food pattern and less on the quality of $\mathrm{diet}^{7}$. Therefore information on the prevalence of stunting and wasting of infants and children in the absence of information on micronutrient status may not be sufficient to judge the nutritional health status ${ }^{8}$.

This paper reports the nutritional health status of 612-month-old disadvantaged infants living in two adjacent peri-urban communities historically known as black and 'coloured' communities. We compare the nutritional status of the two groups using both anthropometric and biochemical information.

\section{Methods}

\section{Study area and design}

The study was done between February and June 1998. The study population came from two adjacent peri-urban communities in the Western Cape, South Africa. The two communities were historically categorised as being 'coloured' (Cloetesville) and black (Kayamandi). It was a cross-sectional study. The aim was to establish the nutritional status of 6-12-month-old disadvantaged infants in these two urban communities. From each of the two communities, 60 children aged 6-12 months were randomly selected from clinic records. Children visiting the clinic who did not have a clinic record were also included in the sampling procedure to ensure maximum representation of the 6-12 month age group in these communities. Appointments were made with the mothers to visit the local day clinic on three occasions during the week to enable the repetition of some of the measurements. Data collection was done over a period of four months. Those who defaulted were visited and accommodated during another session. If a mother-child pair did not default they would complete their three visits within a period of two weeks. In each community two research assistants were trained in all aspects of data collection. The Medical Research Council gave ethical approval for the study.

\section{Antbropometry}

Measurements of weight and length were taken without shoes and in light clothing as described by Jelliffe and Jelliffe 9 . Weight of both infant and mother was measured to the nearest $0.1 \mathrm{~kg}$ using a calibrated electronic load cell digital scale (UC-300 Precision Health Scale). Length of infants was measured in the recumbent position on a baby board to the nearest $0.1 \mathrm{~cm}$. Height of mothers was measured using a stadiometer attached to a wall. Anthropometric indicators including $Z$-scores for heightfor-age (HAZ), weight-for-age (WAZ) and weight-forheight (WHZ) were calculated using the Epi Info version $6.04 \mathrm{a}$ software program ${ }^{10}$. The prevalence of stunting, underweight and wasting was defined as the percentage of individuals who had a HAZ, WAZ and WHZ score below minus two standard deviations $(-2 \mathrm{SD})$ of the National Center for Health Statistics (NCHS) reference median ${ }^{11}$. The severity of undernutrition was categorised according to the World Health Organization (WHO) categories $^{12}$. Information on low birth weight was obtained from clinic records.

\section{Laboratory analyses}

A venous blood sample was collected from each infant. Whole blood was analysed on a Coulter Counter for haemoglobin value $(\mathrm{Hb})$. Serum ferritin concentration was determined immunoradiometrically (Becton Dickinson). Total iron and total iron binding capacity (TIBC) were analysed using Boehring Mannheim kits (catalogue numbers 125806 and 1553704, respectively). Transferrin saturation was calculated by expressing total serum iron as a percentage of total iron binding capacity. Plasma retinol was determined using a slightly modified version of the reversed-phase high-performance liquid chromatography (HPLC) method described by Catignani and Bieri ${ }^{13}$. Serum zinc was determined through atomic absorption spectrometry. The determination of C-reactive protein (CRP) was done by particle-enhanced nephelometry ( $N$ Latex CRP, Boehring).

\section{Morbidity}

A morbidity questionnaire was completed for each child during the first visit. Information on the occurrence of diarrhoea, upper respiratory tract infections, skin infections and the presence of other illness was collected. A paediatrician gave each child a full physical examination after anthropometric measurements were taken. Children who presented with serious health problems were referred to the local hospital.

\section{Dietary intake}

Dietary intake was measured in triplicate by 24-hour dietary recall. A registered dietician trained the research assistants of both communities in the methodology of the 24-hour recall during a mutual training session prior to the study. During a pilot study on 20 children the research assistants were observed while fulfilling their activities and final adjustments were made to their methods. Recalls included weekdays and weekends over a period of two weeks to ensure that the information collected reflected the habitual diet. Data on breast-feeding and weaning practices were also collected by questionnaire. This questionnaire included questions on duration of breastfeeding, weaning practices and introduction of complementary food. Breast milk consumption was estimated ${ }^{14,15}$ at $750 \mathrm{ml} \mathrm{day}^{-1}$. Dietary data were encoded using the MRC food composition tables ${ }^{16}$. Portion sizes were estimated according to the MRC food quantities manual ${ }^{17}$. The dietary intake was compared with the Recommended Dietary Allowances (RDAs) ${ }^{18}$. 


\section{Denver Developmental Screening Test (DDST)}

A questionnaire determining the level of mental and motor development of each child was administered to all children aged 6-12 months ${ }^{19}$. For this age group items of the age range 4.9-13.5 months were selected so as to include easy and more difficult items to accommodate children of all levels of development. There are four categories in the test, namely personal social, language, gross motor and fine motor. The research assistants scored the test based on observations and recalls from both themselves and the mothers. Each child's score was calculated by expressing the number of positive observations as a percentage of the maximum possible positive observations. The DDST scores were calculated as the number of positive scores. Each mother and child were interviewed in a separate room to ensure a peaceful and quiet environment as well as a consistent environment for repeat measures. Fieldworkers had been thoroughly trained to ensure correct and consistent execution of the test items.

\section{Statistical analyses}

The SPSS statistical package version 9.0 was used for data analyses. The $t$-test was used to test for differences between continuous variables with equal variances. For unequal variances, the Wilcoxon signed rank test was used.

\section{Results}

\section{Sociodemographic information}

Both communities had low socio-economic status. Using socio-economic criteria the black community was clearly more disadvantaged than the coloured community. In the black community the majority of people (80\%) lived in informal housing whilst in the coloured community the majority (94\%) lived in brick houses. Only 11\% of black households had access to water in their homes as opposed to $81 \%$ of coloured households. A similar distribution was apparent with regard to sanitation. Only 11\% of black residents had toilet facilities in their dwellings compared with $79 \%$ of coloured residents. The majority of coloured households (93\%) owned a refrigerator, while 55\% of black households owned a refrigerator. In both communities more than 90\% had electricity in their homes. However, only 39\% of black people used electricity for cooking as opposed to $100 \%$ in the coloured community. Gas and paraffin were used as alternative means of cooking.

\section{Antbropometry}

Table 1 shows the general characteristics of the study population. There was very little difference between the two communities with respect to mean weight and height. The only significant difference was in weight-for-age $Z$-score (WAZ). The coloured children had a significantly
Table 1 General characteristics of the study population

\begin{tabular}{lccccc}
\hline & \multicolumn{2}{c}{ Coloured } & & \multicolumn{2}{c}{ Black } \\
\cline { 2 - 3 } \cline { 6 - 6 } \cline { 5 - 6 } & Mean & SD & & Mean & SD \\
\hline Age (months) & 8.9 & 1.9 & & 8.3 & 1.5 \\
Length (cm) & 68.6 & 4.9 & & 68.3 & 2.7 \\
Lower leg length (mm) & 186.0 & 14.0 & & 185.0 & 13.0 \\
Weight (kg) & 8.6 & 1.7 & & 8.8 & 1.2 \\
WAZ & -0.16 & 1.42 & & 0.31 & 1.12 \\
HAZ & -0.95 & 1.30 & & -0.73 & 0.84 \\
WHZ & 0.76 & 1.12 & & $1.10^{*}$ & 1.01 \\
Underweight (\%) & 8 & - & & 2 & - \\
Stunting (\%) & 18 & - & & 7 & - \\
Wasting (\%) & 0 & - & & 0 & - \\
\hline
\end{tabular}

${ }^{*} P<0.05$.

lower mean WAZ score than the black children. Stunting was present in $18 \%$ of coloured and $7 \%$ of black infants. Underweight was prevalent in $8 \%$ of coloured and in $2 \%$ of black infants. There was no wasting in either of the two communities. The prevalence of low birth weight (birth weight $<2500 \mathrm{~g}$ ) was $28 \%$ in coloured children and $10 \%$ among blacks. Maternal height did not differ between the two communities; however, weight and body mass index (BMI) were higher in the black women.

\section{General bealth}

Twenty-eight per cent of black children and 23\% of coloured children were reported to have had diarrhoea during the two weeks prior to the clinic visit. Upper respiratory tract infections were reported in 39\% of black and $74 \%$ of coloured children during the same period. Skin infections were present in $27 \%$ of black and $12 \%$ of coloured children.

\section{Micronutrients}

Table 2 shows that mean levels of haemoglobin, serum retinol and albumin were significantly lower in black than in coloured infants. Table 3 shows the prevalence of micronutrient deficiencies. Marginal vitamin A deficiency was especially prevalent among blacks (23\%). A high number of both coloured (64\%) and black (83\%) infants were anaemic. The prevalence of

Table 2 Biochemical indices of the study population

\begin{tabular}{|c|c|c|}
\hline & Coloured $(n=42)$ & Black $(n=47)$ \\
\hline & Mean (SD) & Mean (SD) \\
\hline Haemoglobin $\left(\mathrm{g} \mathrm{dl}^{-1}\right)$ & $10.7(0.7)^{\star}$ & $10.4(0.8)$ \\
\hline Haematocrit & $31.3(2.0)$ & $31.1(2.5)$ \\
\hline Serum retinal $\left(\mu \mathrm{g} \mathrm{dl}^{-1}\right)$ & $29.1(5.7)^{*}$ & $24.9(8.0)$ \\
\hline Albumin $\left(\mathrm{gl}^{-1}\right)$ & $49.0(3.2)^{*}$ & $47.2(4.0)$ \\
\hline Total iron $\left(\mu \mathrm{moll}^{-1}\right)$ & $9.3(3.8)$ & $7.8(4.2)$ \\
\hline TIBC $\left(\mu \mathrm{moll}^{-1}\right)$ & $67.4(9.1)$ & $64.6(10.2)$ \\
\hline Ferritin $\left(\mathrm{ng} \mathrm{ml}^{-1}\right)$ & $15.3(11.2)$ & $19.0(14.3)$ \\
\hline$\%$ Transferrin saturation & $14.2(6.2)$ & $12.3(6.4)$ \\
\hline Serum zinc $\left(\mu \mathrm{gdl}^{-1}\right)$ & $72.0(13.3)$ & $74.2(13.5)$ \\
\hline
\end{tabular}

${ }^{*} P<0.05$. 
Table 3 Prevalence (\%) of micronutrient deficiencies in study population

\begin{tabular}{lcc}
\hline & Coloured $(n=42)$ & Black $(n=47)$ \\
\hline Haemoglobin $<11 \mathrm{~g} \mathrm{dl}^{-1} \dagger$ & 64 & 83 \\
Total iron $<5.4 \mu \mathrm{moll}^{-1} \ddagger$ & $26^{*}$ & 50 \\
TIBC $>86.0 \mu \mathrm{moll}^{-1} \ddagger$ & 4 & 2 \\
Ferritin $<10 \mathrm{ng} \mathrm{m}^{-1} \ddagger$ & 34 & 39 \\
Transferrin saturation $<8 \% \ddagger$ & $26^{*}$ & 48 \\
Iron-deficiency anaemia§ & 32 & 46 \\
Vitamin $\mathrm{A}<20 \mu \mathrm{g} \mathrm{dl}^{-1} \uparrow$ & $2^{* *}$ & 23 \\
Vitamin $\mathrm{A}<10 \mu \mathrm{g} \mathrm{dl}^{-1}$ & 0 & 2 \\
Serum zinc $<65 \mu \mathrm{g} \mathrm{dl}^{-1} \ddagger$ & 35 & 32 \\
C-reactive protein $>5 \mathrm{mgl}^{-1} \|$ & 7 & 38 \\
\hline
\end{tabular}

${ }^{*}, P<0.05 ;{ }^{* *}, P<0.01$.

+ $\mathrm{WHO}^{20}$.

$\neq$ Pilch and Senti ${ }^{21}$.

$\S \mathrm{Hb}<11 \mathrm{~g} \mathrm{dl}^{-1}$ and ferritin $<10 \mathrm{ng} \mathrm{ml}^{-1}$ or transferrin saturation $<8 \%$. 9 WHO/UNICEF ${ }^{22}$.

\| Pepys ${ }^{23}$.

low serum iron in black children (50\%) was twice that in coloured children (26\%). The prevalence of low serum ferritin was similar in coloured (34\%) and black (39\%) infants. Both communities had a similar prevalence of zinc deficiency. C-reactive protein, an indicator of infection, was considerably higher in black children (38\%) than in coloured children (7\%). Infants with high CRP level had significantly $(P<0.05)$ higher ferritin levels than those with low CRP level.

Zinc deficiency in the presence of iron deficiency was observed in $21 \%$ of black and $4 \%$ of coloured infants. Eleven per cent of black infants and $2 \%$ of coloured infants had vitamin A deficiency together with iron deficiency. Vitamin A deficiency in the presence of zinc deficiency was prevalent among $7 \%$ of black infants. Vitamin A deficiency together with zinc and iron deficiency was present among $4 \%$ of black infants.

\section{Dietary intake}

Most nutrients, apart from vitamin C, were consumed in lesser amounts by black compared with coloured children
Table 5 Denver Developmental Screening Test scores of infants

\begin{tabular}{lclc}
\hline & Coloured $(n=39)$ & & Black $(n=59)$ \\
\cline { 2 - 2 } & Mean (SD) & & Mean (SD) \\
\hline Personal social & $0.97(0.07)^{\star \star}$ & & $0.62(0.17)$ \\
Language & $0.78(0.16)^{\star \star}$ & & $0.48(0.14)$ \\
Fine motor & $0.94(0.1)^{\star}$ & & $0.90(0.17)$ \\
Gross motor & $0.91(0.20)^{\star *}$ & & $0.76(0.23)$ \\
Total score & $0.90(0.12)^{\star \star}$ & & $0.75(0.21)$ \\
\hline
\end{tabular}

${ }^{*}, P<0.01 ;{ }^{* *}, P<0.001$

(Table 4). Also apparent is the percentage of infants in the black community who consumed less than $67 \%$ of the RDA. In particular, the intakes of iron, zinc and vitamin D were low.

\section{Denver Developmental Screening Test}

It is very clear that there was a great difference in the DDST scores between the two groups of children (Table 5), hence the difference in total scores. The two groups showed similarities only in the fine motor development scores.

\section{Discussion}

This study indicates that data on stunting and wasting alone are not sufficient indicators for nutritional status of infants in different communities. In order to judge health risks adequately, information on the micronutrient status of such communities is essential.

The weight-for-age $Z$-scores observed in the coloured infants were significantly lower than in the black infants. This difference is difficult to explain. However, an explanation may be found in the fact that the prevalence of low birth weight is higher in the coloured than in the black infants. The question may be asked whether the NCHS reference values are applicable to these communities. However, Ulijaszek concluded that, although the

Table 4 Dietary intake of study population

\begin{tabular}{|c|c|c|c|c|c|}
\hline & \multicolumn{2}{|c|}{ Coloured $(n=48)$} & \multicolumn{2}{|c|}{ Black $(n=62)$} & \multirow[b]{2}{*}{$\mathrm{RDA}^{18}$} \\
\hline & Mean (SD) & $<67 \%$ RDA & Mean (SD) & $<67 \%$ RDA & \\
\hline Energy (MJ) & $3.9(0.9)^{\star \star \star}$ & 2 & $3.2(0.8)$ & 13.4 & 3.5 \\
\hline Energy from protein (\%) & $14(4)$ & - & $10(3)$ & - & $10-15 \%$ \\
\hline Energy from fat (\%) & $38(6)$ & - & $38(8)$ & - & $30-40 \%$ \\
\hline Energy from carbohydrates (\%) & $48(6)$ & - & $53(6)$ & - & $50-60 \%$ \\
\hline Total protein $(\mathrm{g})$ & $32(13)$ & 4 & $19(7)$ & 21 & 14 \\
\hline Vitamin A (retinol equivalents, RE) & $942(410)^{*}$ & 0 & $713(351)$ & 6 & $375 \mathrm{RE}$ \\
\hline Vitamin $C(\mu \mathrm{g})$ & $68(28)$ & 0 & $77(43)$ & 0 & 35 \\
\hline Vitamin D $(\mu \mathrm{g})$ & $7(4)^{*}$ & 50 & $5(4)$ & 57 & 10 \\
\hline Vitamin E $(\mu \mathrm{g})$ & $7(3)^{\star \star}$ & 0 & $5(4)$ & 10.4 & 4 \\
\hline Zinc $(\mu g)$ & $5(2)^{\star \star \star}$ & 8 & $4(1)$ & 31 & 5 \\
\hline Folate $(\mu \mathrm{g})$ & $88(25)^{\star \star \star}$ & 0 & 65 (18) & 3 & 35 \\
\hline Iron $(\mu \mathrm{g})$ & $9(5)^{\star}$ & 25 & $7(5)$ & 47 & 10 \\
\hline Calcium $(\mu \mathrm{g})$ & $768(349)^{\star \star \star}$ & 0 & $522(231)$ & 8 & 400 \\
\hline Magnesium $(\mu \mathrm{g})$ & $123(43)^{\star \star \star}$ & 0 & $82(35)$ & 0 & 40 \\
\hline
\end{tabular}

${ }^{*}, P<0.05 ;{ }^{* *}, P<0.01 ;{ }^{* *}, P<0.001$. 
NCHS references have limitations, all major population groupings have a similar growth potential. He argues that observed differences could largely be ascribed to differences in environmental quality experienced: growth is influenced largely by nutritional status and exposure to and treatment of infectious diseases ${ }^{24}$. A study by Droomers et al. supported this by observing Indonesian pre-school children of high socio-economic class growing taller and heavier than the NCHS reference population ${ }^{25}$. Another observation was the higher BMI in the black women compared with the coloured women. High BMI is often observed in black women in South Africa ${ }^{26}$.

The prevalence of common illnesses such as diarrhoea, upper respiratory tract infection and skin infections was high in these communities. The high prevalence of micronutrient deficiency could play a crucial role in the aetiology of these infections ${ }^{27-30}$. However, one would expect the prevalence of illness to be higher in the black community owing to the higher prevalence of marginal vitamin A deficiency and elevated C-reactive protein concentration $^{31,32}$. The data on infection were predominantly qualitative. Thus it may be that the black children had sub-clinical infections not picked up during the investigation. The high prevalence of elevated C-reactive protein levels in the black children also explains the slightly higher ferritin levels in these children. Ferritin is known to increase with infection. The poor living conditions of the black children may also contribute to the higher prevalence of infections.

The presence of multiple micronutrient deficiencies is an important finding. Many nutrition intervention studies focus on one micronutrient only. In the light of the findings of this study it would be crucial to address micronutrient deficiencies in similar communities with a multiple micronutrient approach. Giving only one micronutrient, e.g. zinc, may potentially be detrimental to a child in creating a higher prevalence of iron deficiency, as zinc and iron compete for absorption in the body ${ }^{33}$.

The dietary intake information provides some explanation for the biochemical deficiency seen in this population. It was clear from the repeat 24-hour recall data that the black children did not consume food sufficient in zinc, iron, vitamin D and total energy. The $47 \%$ and $31 \%$ of black infants consuming less than $67 \%$ of the RDA for iron and zinc, respectively, support this observation. In the coloured community, only iron consumption was significantly less than the RDA (25\%). The early introduction of complementary food may also contribute to the deficiencies in micronutrients. In both communities the average age of introduction of complementary food was less than 4 months. However, there was a difference in the kind of food introduced in these two communities. The coloured children often received cooked vegetables prepared as part of the adult meals. Although the black children also received traditional food it was most often only maize porridge, which is high in energy but insufficient in essential micronutrients. An important factor to consider is the introduction of commercially manufactured baby foods as a major food source in especially the black children. These products were consumed by more than $80 \%$ of black and approximately $70 \%$ of coloured children on a regular basis. One may argue that these foods should supply enough nutrients to address the micronutrient needs of these children. However, the 24-hour dietary recall data showed that the majority of mothers use these products in a diluted form, so much so that they cannot possibly supply the required daily needs. If these products are the major source of food for some of these infants one can understand the existing deficiencies.

The results from the psychomotor developmental test also showed large differences between the two communities. The performance of the black infants was lower compared with the coloured infants. The higher prevalence of deficiencies in iron and zinc may have contributed to these differences. Many studies have shown that among undernourished children, mental ${ }^{34-36}$ and motor development $\mathrm{t}^{37,38}$ are often below normal. The level of poverty may also contribute to the test results. These children come from homes where often five or six people live in two rooms. Exposure to toys and other forms of stimulation very often does not exist.

Results from this study show that deficiencies in iron, zinc and vitamin A remain a concern among urban disadvantaged coloured and black children. These deficiencies are more prominent among the children of the black community, which comprise the major South African population group. With an increasing urban black population, the magnitude of the problem may become a serious public health problem.

\section{Acknowledgements}

The authors offer their sincere thanks to the fieldworkers, Sr Mary Mosomothame, Lucia Tembani, Yolandi Fernandez and Celesté Manual, for their persistent hard work under difficult circumstances; to the communities of Kayamandi and Cloetesville for their co-operation; to $\mathrm{Mr}$ Harmse, head of the local health department, for permission to work in the community; to MSc students Jitske Brouwer and Annuska Visscher of Wageningen University for their assistance in many aspects of the study; and to Mr and Mrs Marais and Mr Harmse for laboratory analyses. The project was funded by the Dutch Foundation for the Advancement of Research in the Tropics (WOTRO) and Nestlé South Africa.

\section{References}

1 Kikafunda JK, Walker AF, Collett D, Tumwine JK. Risk factors for early childhood malnutrition in Uganda. Pediatrics 1998; 102: E45. 
2 Getaneh T, Assefa A, Tadesse Z. Protein energy malnutrition in urban children: prevalence and determinants. Ethiopian Med.J. 1998; 36: 153-66.

3 Dannhauser A, Bester C, Joubert G, Badenhorst P, Slabber M, Badenhorst A, Du Toit E, Barnard H, Botha P, Nogabe L. Nutritional status of pre-school children in informal settlement areas near Bloemfontein, South Africa. Public Health Nutr. 2000; 3: 303-12.

4 Faber M, Benadé AJS. Nutritional status and dietary practices of 4-24 month old children from a rural South African community. Public Health Nutr. 1999; 2: 179-85.

5 Jaspers S, Shoham J. Targeting the vulnerable: a review of the necessity and feasibility of targeting vulnerable households. Disasters 1999; 23: 359-72.

6 Vazir S, Naidu AN, Vidyasagar P. Nutritional status, psychosocial development and the home environment of Indian rural children. Indian Pediatr. 1998; 35: 959-66.

7 Faber M, Oelofse A, Kriek JA, Benadé AJS. Breastfeeding and complementary feeding practices in a low socio-economic urban and a low socio-economic rural area. S. Afr. J. Food Sci. Nutr. 1997; 9: 43-51.

8 Oelofse A, Faber M, Benadé JG, Benadé AJS, Kenoyer DG. The nutritional status of a rural community in KwaZuluNatal, South Africa: the Ndunakazi project. Central Afr. J. Med. 1999; 45: 14-9.

9 Jelliffe DB, Jelliffe EF. Community Nutritional Assessment. With Special Reference to Less Developed Countries. Oxford: Oxford University Press, 1989.

10 Dean AG, Dean JA, Burton AH, Dicker RC. Epi Info, Version 6.04a: A Word Processing, Database and Statistics Program for Epidemiology on Microcomputers. Stone Mountain, GA: USD, Inc., 1993.

11 Gorstein J, Sullivan K, Yip R, De Onis M, Trowbridge F, Fajans P, Clugston G. Issues in assessment of nutritional status using anthropometry. Bull. World Health Org. 1994; 72(2): 273-83.

12 De Onis M, Monteiro C, Akré J, Clugston G. The worldwide magnitude of protein-energy malnutrition: an overview from the WHO Global Database on Child Growth. Bull. World Health Org. 1993; 71: 703-12.

13 Catignani GL, Bieri JG. Simultaneous determination of retinol and alpha-tocopherol in serum or plasma by liquid chromatography. Clin. Chem. 1983; 29(4): 708-12.

14 Suitor CW, Olson C, Wilson J. Nutrition care during pregnancy and lactation: new guidelines from the Institute of Medicine. J. Am. Diet. Assoc. 1993; 93: 478-9.

15 Wood CS, Isaacs PC, Jensen M, Hilton HC. Exclusively breast-fed infants: growth and caloric intake. Pediatr. Nurs. 1988; 14: 117-24.

16 Langenhoven ML, Kruger M, Gouws E, Faber M. Medical Research Council Food Composition Tables, 3rd ed. Tygerberg, South Africa: MRC, 1991.

17 Langenhoven ML, Kruger M, Gouws E, Faber M. Medical Research Council Food Quantities Manual, 3rd ed. Tygerberg, South Africa: MRC, 1991.

18 Subcommittee on the Tenth Edition of the RDAs, Food and Nutrition Board Commission on the Life Sciences National Research Council. Recommended Dietary Allowances, 10th ed. Washington, DC: National Academy Press, 1989.

19 Frankenburg WK, Dodds JB. The Denver Developmental Screening Test. J. Pediatr, 1967; 71: 181-91.

20 World Health Organization (WHO). Nutritional Anaemia. WHO Technical Report Series No. 3. Geneva: WHO, 1972.

21 Pilch SM, Senti FR, eds. Assessment of the Iron Nutritional
Status of the US Population Based on Data Collected in the Second National Health and Nutrition Examination Survey 1976-1980. Bethesda, MD: Life Services Research Office, Federation of the American Societies for Experimental Biology, 1984.

22 World Health Organization (WHO)/United Nations Children's Fund (UNICEF). Indicators for Assessing Vitamin A Deficiency and Their Application in Monitoring and Evaluating Intervention Programmes. Report on a joint WHO/UNICEF consultation, Geneva, 9-11 November 1992. Review version. Geneva: WHO, 1994; 1-56.

23 Pepys MB. C-reactive protein fifty years on. Lancet 1981; 1(8221): 653-7.

24 Ulijaszek SJ. Between-population variation in pre-adolescent growth. Eur. J. Clin. Nutr. 1994; 48: S5-14.

25 Droomers M, Gross R, Schultink W, Sastroamidjojo S. High socio economic class preschool children from Jakarta, Indonesia are taller and heavier than NCHS reference population. Eur. J. Clin. Nutr. 1995; 49: 740-4.

26 Oelofse A, Jooste PL, Steyn K, Badenhorst CJ, Langenhoven ML. The lipid and lipoprotein profile of the African population of the Cape Peninsula. S. Afr. Med.J. 1996; 86: $162-6$.

27 Tomkins A. Nutritional status and severity of diarrhoea among pre-school children in rural Nigeria. Lancet 1981; 1: $860-2$.

28 Sepulveda J, Willett W, Munoz A. Malnutrition and diarrhoea: a longitudinal study among urban Mexican children. Am. J. Epidemiol. 1988; 127: 365-76.

29 Black RE. Would control of childhood infectious diseases reduce malnutrition? Acta Paediatr. Scand. Suppl. 1991; 374: $133-40$

30 Black E. Therapeutic and preventive effects of zinc on serious childhood infectious diseases in developing countries. Am. J. Clin. Nutr. 1998; 68: 476S-9S.

31 Nestel P, Malera A, Rosado J, Mora JO. Vitamin A deficiency and anaemia among children 12-71 months old in Honduras. Rev. Panam. Salud Publica 1999; 6(1): 34-43.

32 Dudley L, Hussey G, Huskisson J, Kessow G. Vitamin A status, other risk factors and acute respiratory infection morbidity in children. S. Afr. Med.J. 1997; 87: 65-70.

33 Solomons NW. Competitive interaction of iron and zinc in the diet: consequences for human nutrition. J. Nutr. 1996; 116(6): 927-35.

34 Lasky RE, Klein RE, Yarbrough C, Engle PL, Lechting A, Martorell R. The relationship between physical growth and infant behavioural development in Guatemala. Child Dev. 1981; 52: 219-26.

35 Martorell R, Rivera J, Kaplowitz H, Pollitt E. Long term consequences of growth retardation during early childhood. In: Hernandez M, Argente J, eds. Human Growth: Basic and Clinical Aspects. Amsterdam: Elsevier Science Publishers, 1992; 143-9.

36 Grantham-McGregor SM, Walker SP. Stunting and mental development in children. Nutr. Res. 1996; 16: 1821-8.

37 Pollit E, Husaini MA, Harahap H, Halati S, Nugraheni A, Sherlock AO. Stunting and delayed motor development in rural West Java. Am. J. Hum. Biol. 1994; 6: 627-35.

38 Powell CA, Walker SP, Himes JH, Fletcher PD, GranthamMcGregor SM. Relationship between physical growth, mental development and nutritional supplementation in stunted children: the Jamaican study. Acta Paediatr. 1995; 84: $22-9$. 